\title{
COMPREHENSIVE REVIEW OF VARIOUS CORROSION BEHAVIOURS ON 316 STAINLESS STEEL
}

\author{
K. Baranidharan ${ }^{1}$, S. Thirumalai Kumaran ${ }^{2 *}$, M. Uthayakumar ${ }^{2}$, \\ P. Parameswaran ${ }^{3}$ \\ ${ }^{1}$ Department of Automobile Engineering, Kalasalingam Academy of Research and \\ Education, Krishnankoil-626126, Tamil Nadu, India. \\ ${ }^{2}$ Faculty of Mechanical Engineering, Kalasalingam Academy of Research and \\ Education, Krishnankoil-626126, Tamil Nadu, India. \\ ${ }^{3}$ Metallurgy and Materials Group, Indira Gandhi Centre for Atomic Research, \\ Kalpakkam-603102, Tamil Nadu, India.
}

Received 07.10.2020

Accepted 11.12.2020

\begin{abstract}
Corrosion is a destructive process that converts the pure metal into a chemically stable form by hydroxide or sulphide, and it is a slow process of destruction on the material by the chemical or electrochemical reaction in the environmental space. This kind of destruction has been typically produced from oxides or salt content on the material, and it results in distinctive orange colouration. The classifications of corrosion act on atmospheric air and liquids as well as on the contact of two solids. To resist the corrosion rate, stainless steel 316 has been chosen because of the presence of 2-3\% molybdenum content, and the presence of molybdenum plays a vital role in corrosion resistance. In this study, literature related to various works has been reviewed to explain the corrosion behaviour on cavitation, crevice, electrochemical, erosion, fatigue, galvanic, uniform, pitting, and stress corrosion which act on 316 stainless steel. In the present work, several coating processes and the additives that have been added to SS 316 to enhance the outcomes according to various corrosion causes are discussed.
\end{abstract}

Keywords: corrosion resistance; 316 stainless steel; material damage; microstructure studies.

${ }^{*}$ Corresponding author: S. Thirumalai Kumaran, thirumalaikumaran@yahoo.com 


\section{Introduction}

Corrosion is a process that is linked with rust on the steel and the oxidation of other metals. It is defined that "the deterioration of a metal with its changes in properties which react with chemical conditions". There are several classifications of corrosion that destroy the material and they are cavitation, crevice, electrochemical, erosion, fatigue, galvanic, uniform, pitting, and stress corrosion, which are discussed in this present literature survey. Stainless steel 316 is a high corrosion resistance material that contains $2-3 \%$ molybdenum, $10 \%$ nickel, $16 \%$ chromium. This work attempts to study the behaviour of stainless steel 316 while reacting with every corrosion type and in some corrosion cases, the coatings or additives have been added to enhance better corrosion resistance compared to the pure form of stainless steel 316 .

\section{Corrosion studies on 316 SS}

\section{Cavitation Corrosion}

The cavitation corrosion is formed when the operating pressure is dropped below the vapour pressure of the fluid. During this scenario, the gas bubbles are formed, and they get collapsed at an increased velocity on the surface of the material. It causes initial cavitation and Table 1 represents the experimental works that are done on stainless steel 316.

Table 1. Benchmarking on experimental works in cavitation corrosion.

\begin{tabular}{lccc}
\hline Authors & Cavitation erosion test & Laser surface & Hardness \\
\hline Arora et al. [1] & $\checkmark$ & $\checkmark$ & \\
Lo et al. [2] & $\checkmark$ & $\checkmark$ & \\
Yucheng Lei et al. [3] & $\checkmark$ & & $\checkmark$ \\
\hline
\end{tabular}

Various ranges of impingement angles have been taken for implementing a noncirculating type test rig to determine the cavitation behaviour of a zirconium-based bulk metallic glass [1]. From a reasonable study, it is clear that hydro turbine steel has been frequently used and computed on these test conditions. When bulk metallic glass (BMG) is compared with hydro turbine steel based on short impingement angles, it closely results in higher erosion resistance. On this basis, BMG has improved erosion behaviour, and it results in high cavitation resistance compared to hydro turbine steel. In the absence of grain boundaries and higher hardness, high erosion resistance has been found in the amorphous structure. By adding tungsten carbide powder (WC) with stainless steel 316 and by using laser surface alloying ( $1 \mu \mathrm{m}$ size of convenient source), high cavitation 
erosion resistance has been obtained [2]. The process has been achieved by high power tungsten carbide Nd-YAG laser for surface alloying and the following phases such as Xray spectroscopy, scanning electron microscopy (SEM), optical microscopy, and X-ray diffractometry (XRD) have been investigated. Hence, the result indicates that the improvement in cavitation erosion resistance reaches more than 30 times better results on SS 316 by increasing the tungsten in the solid solution. In ultrasonic cavitation erosion of SS 316L, by using liquid $\mathrm{Pb}-\mathrm{Bi}$ eutectic alloy, the weld joint determines the cavitation behaviour [3]. Long-period cavitation damage has figured out the mapping surface properties and Energy-dispersive X-ray spectroscopy (EDS) has been applied on the elements, especially on the micro-region surface of the weld joint as well as at $19.2 \mathrm{kHz}$, an ultrasonic device is used on lead-bismuth eutectic (LBE), SEM and Atomic Force Microscopy (AFM). The result has shown that the cracks have occurred on the eroded surface after the cavitation period and work hardening bubbles impact on the development stage by strengthening cavitation resistance. Hence, the performance of weld metal has enhanced much better cavitation resistance on stainless steel 316L.

\section{Crevice corrosion}

When the material gets a gap or crack on its joining surfaces, this type of corrosion takes place instantly adjacent to the surface. The damage of crevice corrosion takes place on one side of the metal at the localized area within or close to other joining surfaces. Table 2 illustrates the experimental works that are done on crevice corrosion.

Table 2. Benchmarking on experimental works in crevice corrosion.

\begin{tabular}{lcccc}
\hline Authors & $\begin{array}{c}\text { Crevice } \\
\text { test }\end{array}$ & $\begin{array}{c}\text { Pitting } \\
\text { test }\end{array}$ & $\begin{array}{c}\text { Electrochemical } \\
\text { monitoring }\end{array}$ & $\begin{array}{c}\text { Potentiodynami } \\
\text { c testing }\end{array}$ \\
\hline Salvago et al. [4] & $\checkmark$ & & $\checkmark$ \\
Buhagiar et al. [5] & $\checkmark$ & & $\checkmark$ \\
Dawson \& Ferreira [6] & $\checkmark$ & & $\checkmark$ \\
Chen et al. [7] & $\checkmark$ & & $\checkmark$ \\
Aoyama et al. [8] & $\checkmark$ & & $\checkmark$ \\
Back \& Singh [9] & $\checkmark$ & & $\checkmark$ \\
Jakobsen \& Maahn [10] & $\checkmark$ & & $\checkmark$ \\
Shojaei et al. [11] & $\checkmark$ & & \\
\hline
\end{tabular}


In crevice corrosion, the resistance of SS 316 occurs in $3.5 \%$ sodium chloride solution and natural seawater. It is done after pre-treatment in nitric acid $\left(\mathrm{HNO}_{3}\right)$ [4]. The preheated faults do not cause any unenthusiastic effects to this corrosion and defects on low unprotected surfaces of $\mathrm{HNO}_{3}$ pre-treatment. Hence, pre-treated samples of both sodium chloride $(\mathrm{NaCl})$ solution and seawater samples are taken and the stainless-steel is exposed to sulphide at the concentration shield surface. It comes to the result that the natural seawater reduces in the long run compared to $\mathrm{NaCl}$ solution.

The medical-grade austenitic stainless steel has low-temperature direct current and active plasma carburising [5]. From the study, it is determined that compared to the untreated material, the pitting and crevice corrosion resistance provides better surface composition and direct plasma carburising treatment. By using electrochemical impedance measurement, the propagation of corrosion has been examined [6]. At the initial stage, the pitting corrosion of SS 316 has lower accelerated inhibition or metal dissolution process. The higher frequency capacitance value indicates that active electrochemical dissolution in lower frequency response indicates an accumulative roll, as crevice corrosion is propagated. An instrument has been designed for corrosion in hightemperature water [7]. The crevice corrosion behaviour of stainless steel 304 has been investigated at high-temperature water. The mechanism of crevice structure on the oxidation behaviour has been conversed as a result.

In the crevice corrosion of stainless steel $316 \mathrm{~L}$, the repassivation mechanism has been analysed and persuaded by $\mathrm{SO}_{4}{ }^{2-i o n s}$ [8]. The crevice corrosion is detected and active dissolution of type $316 \mathrm{~L}$ is suppressed by $\mathrm{pH} 0.4$ in anodic polarization measurements. Hence, the result shows the reduction in $\mathrm{pH}$ and repassivation of cavitation corrosion is enhanced. For pulp bleaching plants, the extensively used equipment is stainless steel and duplex [9]. NiCr3127 and 654SMO with Pre numbers 51 and 55 are the most destructive chlorine dioxide bleach plant conditions and they are examined. These are the two issues that cause the occurrence of crevice corrosion and pitting.

A new experiment with a modified device, 'Avesta Cell' has been used to investigate crevice corrosion of AISI 316 [10]. This investigation in the acidified environment indicates the crevice corrosion at low-temperature outcomes from the crevice. The result shows that at the higher temperature, metastable pitting is stabilized by the crevice. In the initiation process of crevice corrosion, the IR drop on stainless steel $316 \mathrm{~L}$ at $3.5 \% \mathrm{NaCl}$ solution is studied [11]. The experiments such as potentiometric, galvanostatic, and some microscopic studies are performed at 30, 60, 120, and $240 \mu \mathrm{m}$ crevice gaps. The result shows the initiation and propagation phases of this corrosion.

\section{Electrochemical corrosion}

The electrochemical corrosion of material appears when the electron present in the atom at the metal surface is transferred to a suitable electron depolarizer. For transporting 
the ions, the solution must be present, and it must act as a medium. Hence, most depolarizations are atmospheric air, acids, and cation of fewer metals. In Table 3, the experimental works that are conducted on electrochemical corrosion are presented.

The pure forms of SS 304 and SS 316 are exposed to atmospheric, seawater splash zone and underground environments to evaluate the corrosion rate for 14 months by adding TSP, chloride, and sulphate in all-weather conditions. Thus, the corrosion rates of SS 304 and SS 316 are compared and represented in Figure 1 [12]. The corrosion rate of SS 316 has experimented in ambient temperature with different solutions of acid concentrations such as sulphuric acid $\left(\mathrm{H}_{2} \mathrm{SO}_{4}\right)$, and phosphoric acid $\left(\mathrm{H}_{3} \mathrm{PO}_{4}\right)$ [13]. This process is performed through potentiostatic polarization methods for the investigation of corrosion. The result shows that the addition of $2 \% \mathrm{NaCl}$ of medium test concentration enhances the active corrosion reactions by anode dissolution. As a result, the magnitude of corrosion is considered as low. Overall corrosion performance in the environment is good from the given solutions [14]. This study has identified the absence of chloride ions and the presence of thiophene derivation of electrochemical behaviour on stainless steel 316. In the Tafel experiment, polarization resistance and electrochemical impedance spectroscopy (EIS) have been performed to investigate the corrosion rate. The result shows TCH $>$ TCA $>$ TCAL $>$ AcT. When the result is compared in anode and cathode, the efficiency of $97 \%$ has been achieved using inhibitors in $0.5 \mathrm{M} \mathrm{H}_{2} \mathrm{SO}_{4}$.

Table 3. Benchmarking on experimental works in electrochemical corrosion.

\begin{tabular}{cccc}
\hline Authors & $\begin{array}{c}\text { Pitting } \\
\text { test }\end{array}$ & $\begin{array}{c}\text { Electrochemical } \\
\text { test }\end{array}$ & $\begin{array}{c}\text { Potentiostatic and dynamic } \\
\text { polarization }\end{array}$ \\
\hline
\end{tabular}

Loto et al. [12]

Galal et al. [13]

Li et al. [14]

Li et al. [15]

Loto $[16]$

La Barbera et al. [17]

Pujar et al. [18]

Yi et al. [19] 


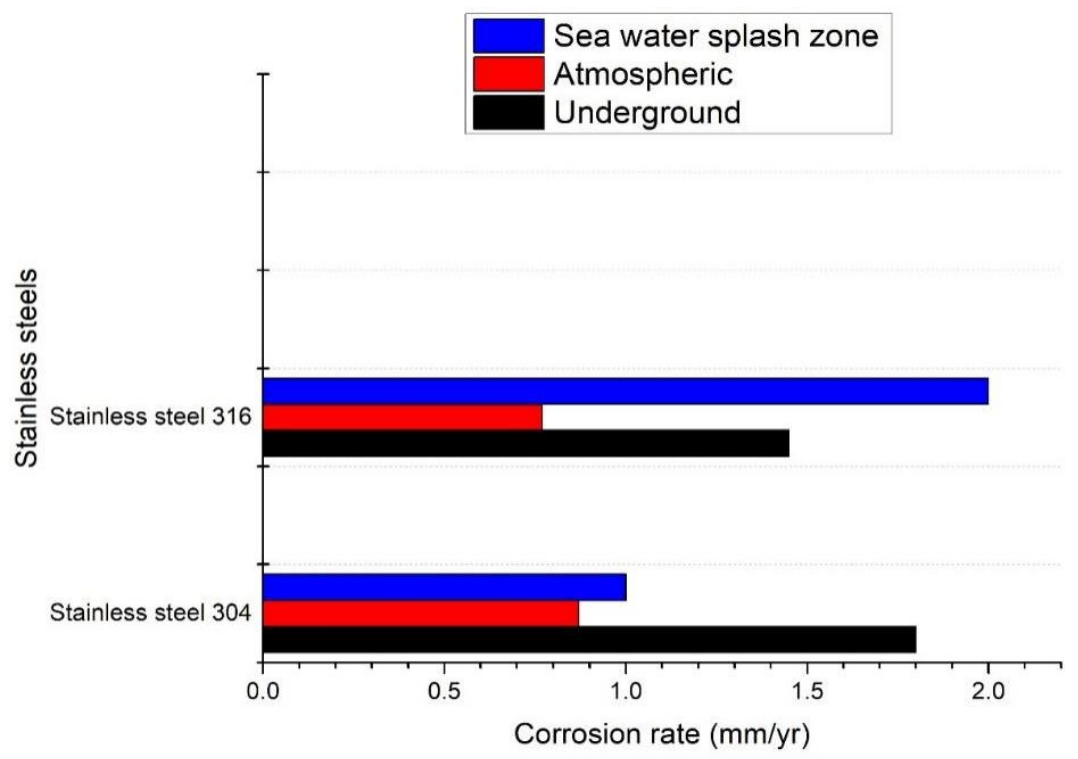

Fig. 1. Comparison of corrosion rate of stainless steel 304 and 316.

The corrosion behaviour of stainless steel 316 has been investigated through hydrochloric acid and acetic acid solutions at $25^{\circ} \mathrm{C}$ by electrochemical techniques [15]. A low concentration of $\mathrm{NaF}$ has no significant influence on SS 316, whereas a high concentration of $\mathrm{NaF}$ reduces passive performance. Consequently, the result shows that the oxide-containing Fions at the surface of the SS 316 component are selectively dissolved.

The corrosion behaviour of SS 316 is simulated in proton exchange membrane fuel cell (PEMFC) with the dilute hydrochloric acid solution at anode environment for bubbling with pure hydrogen at gas $80^{\circ} \mathrm{C}$ and it has been examined in electrochemical measurements [16]. Both the polarization curve and EIS of SS 316 cannot passivate in the environment. Hence, EIS spectra reveal porous corrosion on the steel layer with active distribution in test solutions. SS 316 provides a better corrosion rate at the coating process. The electrochemical noise has generated pitting and the general corrosion of SS 316 in the acidic environment is observed at ambient temperature [17]. The result depicts the average noise power by the spectral standard deviation of noise density and roll-off slope parameters. The noise amplitude increases with decreasing frequency and it is inversely proportional to the power of constant frequency "flicker" noise. From the SEM micrograph, the existence of pitting and general corrosion is identified.

SS 316 with plain carbon steel has been tested by electron beam processing in cladding and alloying [18]. The investigation of electrochemical behaviour is done at different depths in the original surface, in dilute $\mathrm{H}_{2} \mathrm{SO}_{4}$. The microstructure studies are 
X-ray microanalysis and electron microscopy. After the resulting layer, the alloying dilution of chromium is used to enhance its hardness and it is similar to the corrosion behaviour of alloy in lower chromium content. In this study, the microstructure of uniform corrosion behaviour of SS 316 with changing concentrations of $\mathrm{Cr}$ and Mo as well as ferrite content is discussed [19]. For extensive microstructural characterization, a weld metal has been proposed in the oxidizing medium. In SS 316 of potentiodynamic polarization, the behaviour has been examined in sodium chloride solution with a scan rate of potential effect [20]. To enhance the stable pitting resistance of the material, the electric charge density is combined with the critical condition. The experiments of altering the corrosion of SS 304 and SS 316 in aqueous sulfate solution are studied [21]. When the result of the experiments is examined, the sinusoidal square and triangle alternating voltage (AV) range have increased the critical current density of positivists. The result shows that AV has increased the critical current of density and decreased in passive potential by transpressive potential active direction as well as enhanced the current density in the passive regime. From this experimental process and studies, it is clear that both the SS 304 and SS 316 have exhibited the same behaviours in the presence of $\mathrm{AV}$. The corrosion current is a kinetic value and potential is a thermodynamic value. It is dissolution current at the corrosion potential. Both corrosion current and corrosion potential are important factors that connect fundamentally on electrochemistry and corrosion behaviours of materials. The corrosion potential is a mixed potential (also an open-circuit potential or rest potential) in which the anodic dissolution rate of the electrode equals to rate of cathodic reactions (no net current flowing in or out of electrode). The corrosion potentials $\left(\mathrm{E}_{\text {corr }}\right)$ and current densities $\left(\mathrm{i}_{\text {corr }}\right)$ are very important factors for investigating corrosion behaviour.

In this experiment [22], Which was compared to the untreated sample with the potential value of $-0.095 \mathrm{~V}$, treated samples have high corrosion potential values, the data is recorded. From all the studies, all corrosion samples experienced elevated in $\mathrm{E}_{\text {corr }}$ and decrease in $\mathrm{i}_{\text {corr }}$, hence the corrosion resistance is improved.

Stainless steel 316 has been subjected to electrochemical corrosions with six solutions concerning the corrosion rate. The crevice and pitting corrosion tests are also conducted and the corrosion rates are represented in the graphs which are shown in Figures 2 and 3, respectively. It is evident from the results that solution 4 has a low corrosion rate in crevice corrosion and solution 1 has a low corrosion rate in pitting corrosion [23].

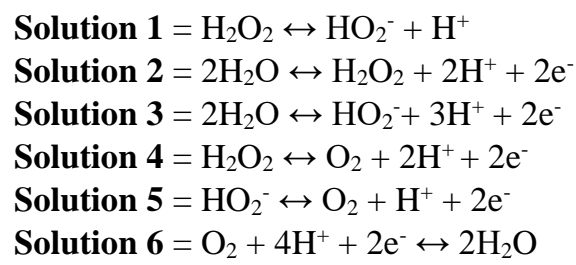




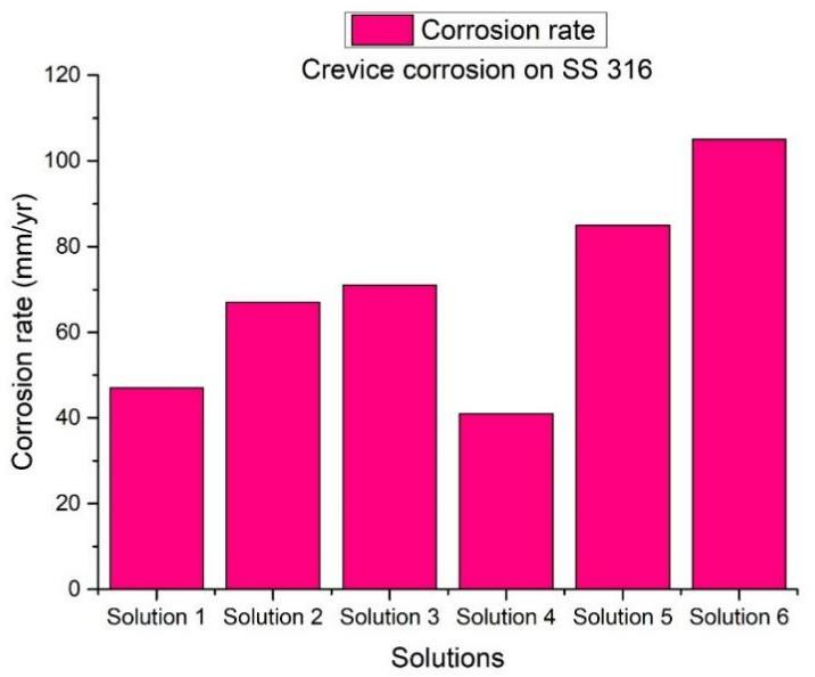

Fig. 2. Electrochemical studies on crevice corrosion.

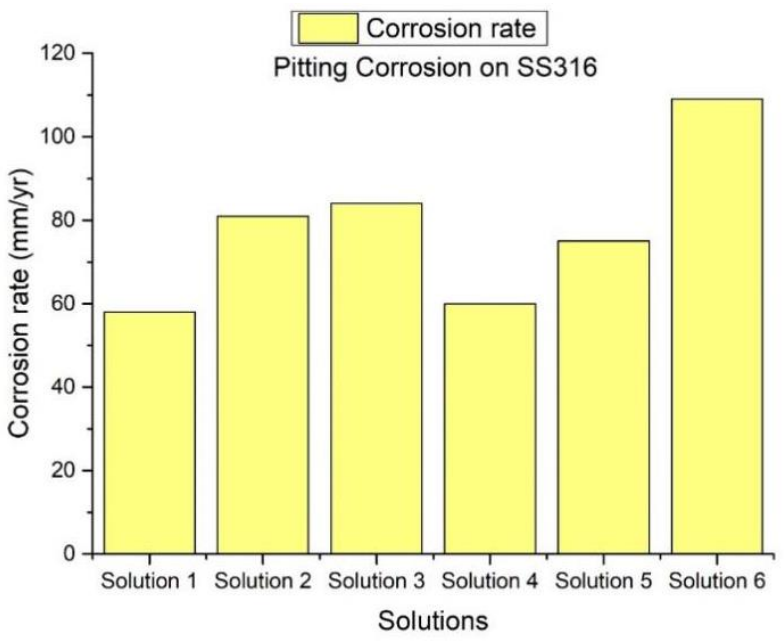

Fig. 3. Electrochemical studies on crevice corrosion.

The experiment imposes a constant potential on the working electrode and measures the resulting current. A potentiostatic experimental imposes a constant potential on the working electrode for s specific period. The measured current is plotted versus time. It is the constant applied voltage with variable current with time (plot I vs. time). For potentiodynamic experiments, the applied potential is increased with time while the current is constantly monitored. The current (or current density) is plotted versus the potential. After the potential is scanned to a predetermined current density or potential, 
the potential scan may be reversed while the current continues to be measured. It is the constant applied voltage with variable potential and current (plot E vs I). A potentiodynamic scan like this is referred to as reverse polarization or cyclic polarization.

\section{Erosion corrosion}

This corrosion is a destructive process of material through mechanical action by impinging, abrasion, liquid particles at fast-flowing in gas, bubbles or dews, and cavitation processes. Experiments have been performed on erosion-corrosion, and they are shown in Table 4.

Table 4. Benchmarking on experimental work in erosion-corrosion.

\begin{tabular}{lcccc}
\hline Authors & $\begin{array}{c}\text { Erosion } \\
\text { corrosion test }\end{array}$ & $\begin{array}{c}\text { Surface } \\
\text { morphology }\end{array}$ & $\begin{array}{c}\text { Electrochemical } \\
\text { measurement }\end{array}$ & Wear \\
\hline
\end{tabular}

Andrews et al. [24]

Li et al. [25]

Yanlin Zhao et al. [26]

Lee et al. [27]

Xiangfeng et al. [28]

Dong et al. [29]

Wood et al. [30]

The test has been performed using an impingement rig in a slurry $3.5 \% \mathrm{NaCl}$ at the angles of $20^{\circ}, 45^{\circ}, 60^{\circ}$, and $90^{\circ}$ the exposed surface results are obtained [24]. The low angle of impingement at $45^{\circ}$ has ductility, and the most critical erosion-corrosion damage occurs at $60^{\circ}$. The influence of Moon ultrasonic cavitation erosion of SS 316L in $\mathrm{NaCl}$ $3.5 \%$ solution has been investigated using an ultrasonic cavitation erosion facility [25]. The specimen has been observed after cavitation erosion by SEM. The result shows that the addition of Mo is decreased and it implies increasing cavitation erosion.

The investigation has been performed to observe the tribo-corrosion wear of SS 316 AISI under two-phase flow and high-speed jet impingement [26]. This work has been attempted to determine the wear by its weight loss, surface characterized, and electrochemical measurement. Here, Silica and sea sand are the two types of sands used to observe the effect of chloride ions. Hence, a short time on the passivation process has been observed on acidic polarization but passivation disappears when the specimen is impinged for a long time. This study has investigated the effect of process in-bed metal 
wastage due to erosion and erosion-corrosion in SS 316 rod [27]. The result as weight loss has been concluded by the experiments with air at room temperature and high fluidizing velocities. Wear happens mainly due to corrosion and it has been determined by wear test at $500^{\circ} \mathrm{C}$. The studies have been performed with high temperature and velocity conditions and they have excellently led to accelerating wear. As a result, the wear rate is less than $3.0 \mathrm{~nm} / \mathrm{h}$ in a radial direction.

Erosion-corrosion measurement has been achieved on low temperature nitrided and non-nitrided SS 316L [28]. Hence, the degree of erosion-corrosion decreases on SS. Low-temperature liquid nitriding, and the material is also decreased. Erosion-corrosion resistance can be enhanced with carburising 50\% and nitriding $70 \%$ at low-temperature plasma alloying [29]. The presence of erosion-corrosion in the material has been investigated through focused ion beam (FIB), transmission electron microscopy (TEM), andsolid particle impact and corrosion of nano-scale are observed by electron microscopy [30].

\section{Fatigue corrosion}

Fatigue corrosion is fatigue in the corrosion environment. The joins and all material actions are mechanically degraded in cyclic loading. It is caused due to engineering loaded conditions, structures, and alternating stress which are harmful to the environment. The experimental works performed on fatigue corrosion are shown in Table 5.

Fatigue corrosion is performed on high and low sulphur of AISI 316 SS which is simulated and pressurized with a water reactor for coolant [31]. Thus, the result shows that the loading frequency decreases, and the crack growth rate of the low specimen is increased. The effect of cold work on microstructure and corrosion fatigue to resist the AISI 316 SS, which contains $0.11 \%$ nitrogen, has been analysed through microscopic study [32]. Based on electrochemical measurements, the corrosion fatigue test and crack propagation have been tested. Hence, the outcome is to increase cold work and critical cracking potential and it decreases by increasing the stress. 
Table 5. Benchmarking on experimental work in fatigue corrosion.

\begin{tabular}{|c|c|c|c|c|}
\hline Authors & $\begin{array}{l}\text { Corrosion } \\
\text { fatigue } \\
\text { test }\end{array}$ & $\begin{array}{c}\text { Fractographic } \\
\text { analysis }\end{array}$ & $\begin{array}{l}\text { Crack and } \\
\text { surface } \\
\text { morphology }\end{array}$ & $\begin{array}{c}\text { Electrochemical } \\
\text { measurements }\end{array}$ \\
\hline Mukahiwa et al. [31] & $\checkmark$ & $\checkmark$ & & \\
\hline Poonguzhali et al. [32] & $\checkmark$ & $\checkmark$ & $\checkmark$ & \\
\hline Jun Gao et al. [33] & $\checkmark$ & & $\checkmark$ & \\
\hline Yawei Peng et al. [34] & $\checkmark$ & $\checkmark$ & $\checkmark$ & \\
\hline Ho-Sub Kim et al. [35] & $\checkmark$ & & $\checkmark$ & $\checkmark$ \\
\hline Ziyu Zhang et al. [36] & $\checkmark$ & & $\checkmark$ & \\
\hline Fereidooni et al. [37] & $\checkmark$ & & $\checkmark$ & \\
\hline
\end{tabular}

SS 316L with different grain sizes and fractions has been obtained by grain boundary treatment [33]. Corrosion fatigue behaviour of SS 316LN has been investigated in lithiated and borated high temperatures. Consequently, no obvious resistance to transgranular cracking is found on low- $\sum$ coincidence lattice boundaries. Regarding this work, the corrosion fatigue cracking mechanism is discussed. In SS $316 \mathrm{~L}$, the influence of low temperature has been investigated and the result shows that the SS 316L has $22 \%$ higher endurance compared to untreated SS 316L [34]. In this experiment, the SS 316L has undergone several tests and it is concluded that the fatigue crack propagation is enhanced by carburized material at high-level stress with the ductility of $10 \mu \mathrm{m}$. Pressurized water reactor (PWR) is used in the environment with $30 \mathrm{ppb}$ of $\mathrm{Zn}$ and peak holding and the low-cycle fatigue (LCF) life of SS 316 are enhanced three times [35]. LCF life and fatigue crack surface are observed along with TEM analysis of crack propagation and it has a good result. Corrosion fatigue (CF) on SS 316 behaviour in elevated-temperature with pressurized water from $373 \mathrm{~K}$ to $598 \mathrm{~K}$ has been investigated at a strain rate of $0.04 \% \mathrm{~s}^{-1}$. This mechanism involves temperature, the effect on $\mathrm{CF}$ crack initiation, and the effect of CF life [36]. Corrosion solutions have an enormous effect on fatigue life and ultrasonic peening has been used to improve the fatigue life in the corrosion environment [37]. The fatigue corrosion life of 316 SS and 347 SS fillers is used and taken as a sample. 


\section{Galvanic corrosion}

Galvanic corrosion is also known as Bimetallic corrosion, which is the electrochemical process of partial interaction of metal rusts with the electrical substance in the presence of an electrolyte. It occurs by the contact of two unrelated metals with each other in corrosive medium or electrolyte. The galvanic corrosion experiments related to surveys have been illustrated in Table 6 .

Table 6. Benchmarking on experimental work in galvanic corrosion

\begin{tabular}{lccc}
\hline Authors & $\begin{array}{c}\text { Electrochemical } \\
\text { noise and } \\
\text { measurement }\end{array}$ & $\begin{array}{c}\text { Electrochemical } \\
\text { impedance } \\
\text { spectroscopy }\end{array}$ & $\begin{array}{c}\text { Galvanic } \\
\text { corrosion } \\
\text { test }\end{array}$ \\
\hline Reza Moshrefi et al. [38] & $\checkmark$ & $\checkmark$ & $\checkmark$ \\
El-Dahshan et al. [39] & $\checkmark$ & $\checkmark$ & $\checkmark$ \\
Matjaz. Finsgar [40] & $\checkmark$ & & \\
\hline
\end{tabular}

From anode and cathode ratios, the tendency of galvanic corrosion of polarization measurement is done [38]. Electrochemical noise (EN) forwards more positive and negative anode/cathode ratios. If the localization index value is 1.005 , then all the measurements in corrosion will indicate the material behaviours. Further,improved work has been done among polarisation measurements, EN results, and EIS. The result shows that in an aggressive environment, galvanic corrosion occurs between the SS 316L and the titanium. This study has been performed to measure open circuit potential (OCP) of single metal and the values of steady-state are formed [39]. The result obtained from this work shows that the OCP acts in SS 316L oxide film formation in seawater and results in pitting attack. Al brass is used as a medium for the disappearing stirred solution. Hence, it is suggested that in seawater, the oxygen content reduces with proper manipulation of $\mathrm{CaCO}_{3}$ film and $\mathrm{Al}$ brass can be greatly reduced to the extent of galvanic corrosion [40].

\section{General or Uniform corrosion:}

Uniform corrosion is formed by oxidizing the steel and the life of the component is estimated comparatively by the simple immersion test result. General corrosion of the material allows the environment to interact with the surface and as a result, the entire metal is exposed to the corrosion-causing condition. Table 7 represents the experiments conducted on general or uniform corrosion. 
Table 7. Benchmarking on experimental work in general corrosion

\begin{tabular}{lcccc}
\hline Authors & $\begin{array}{c}\text { Electrochemical } \\
\text { impedance } \\
\text { spectroscopy }\end{array}$ & $\begin{array}{c}\text { Surface } \\
\text { morphology }\end{array}$ & $\begin{array}{c}\text { General } \\
\text { corrosion }\end{array}$ & $\begin{array}{c}\text { Polarization } \\
\text { experiments }\end{array}$ \\
\hline Moucheng Li et al. [41] & & $\checkmark$ & $\checkmark$ & $\checkmark$ \\
Marin et al. [42] & $\checkmark$ & $\checkmark$ & \\
Hao Yun-wei et al. [43] & $\checkmark$ & $\checkmark$ & $\checkmark$ \\
Xiaoxia Sheng et al. [44] & $\checkmark$ & $\checkmark$ & \\
\hline
\end{tabular}

In the proton exchange membrane fuel cell environment, the corrosion behaviour of SS 316 has been investigated with the coating of titanium nitride (TiN) [41]. The result shows that the TiN coating of SS 316 provides higher corrosion resistance and electric conductivity. Stainless steel has been extensively used for high corrosion resistance with excellent mechanical properties [42]. Thus SS 316, which possesses high molybdenum content, has been taken for this experiment to enhance the corrosion resistance. In atomic layer deposition, $\mathrm{Al}_{2} \mathrm{O}_{3} / \mathrm{TiO}_{2}$ layer coating has been used, and enhanced corrosion resistance has been realized from the microstructure studies.

The stainless steel 316 has been used for corrosion treatment induced by surface mechanical attrition treatment (SMAT) and it has been determined by XRD and SEM [43]. The result shows that the average grain size of $19 \mathrm{~nm}$ of the nanocrystalline layer is produced. From this treatment, the corrosion resistance is enhanced greatly by higher annealing temperatures. The Desulfovibrio desulfuricans and local marine isolate are the two kinds of sulphate-reduced bacteria that are used in this work [44]. From this process, it is clear that by adding this biofilm, the corrosion rate is reduced and an enhanced result, which plays a vital role in SRB cell on localized corrosion, has been obtained.

\section{Pitting corrosion}

Pitting corrosion is known as extremely localized corrosion in which cavities or holes are produced in the material. When comparing the uniform corrosion damage, the pitting corrosion is riskier because it is problematic to detect and predict. The pitting corrosion rate is calculated from the following solution test. These solutions are mentioned as same as in crevice solution samples. The literature survey related to pitting corrosion is illustrated in Table 8 . 
Table 8. Benchmarking on experimental works in pitting corrosion.

\begin{tabular}{lcccc}
\hline Authors & $\begin{array}{c}\text { Pitting } \\
\text { corrosion } \\
\text { test }\end{array}$ & $\begin{array}{c}\text { Electrochemical } \\
\text { measurement }\end{array}$ & $\begin{array}{c}\text { Potentiostatic } \\
\text { and dynamic } \\
\text { polarization }\end{array}$ & $\begin{array}{c}\text { Surface } \\
\text { morphology }\end{array}$ \\
\hline Talebian et al. [45] & $\checkmark$ & $\checkmark$ & $\checkmark$ & $\checkmark$ \\
Prieto et. al. [46] & $\checkmark$ & $\checkmark$ & $\checkmark$ & $\checkmark$ \\
Naghizadeh et. al. [47] & $\checkmark$ & & $\checkmark$ & \\
Zakeri et. al. [48] & $\checkmark$ & & & \\
Liya Guo et. al. [49] & $\checkmark$ & $\checkmark$ & & \\
\hline
\end{tabular}

To investigate the pitting corrosion inhibitors, the sodium (E)-4-(nitro benzylidene amino)-benzoate (SNBB), sodium (E)-4-(benzylidene amino)-benzoate (SBB), and sodium (E)-4-(hydroxy benzylidene amino)-benzoate (SHBB) is the new synthesis bases for SS 304 in neutral $0.1 \mathrm{M} \mathrm{NaCl}$ solution [45]. In this process, the stainless steel 304 increases its pitting corrosion resistance at the localized layer in the passive layer. The stainless-steel specimen is used for direct metal laser sintering (DMLS) and in which, materials corroded with microstructural defects are taken as samples [46] and they are tested. The corrosion resistance has been observed in the ferric chloride pitting test. In stainless steel 316, the effect of dichromate ions on corrosion behaviour has been investigated and the electrochemical measurements are computed using electron microscopy with $0.1 \mathrm{M} \mathrm{NaCl}$ solution [47]. The result shows that the pitting corrosion resistance gets enhanced in the occurrence of $\mathrm{Cr}_{2} \mathrm{O}_{7}{ }^{2-}$ and decreases in metastable pit initiation.

The study has been performed to examine the critical pitting temperature (CPT) on 316 SS and the dichromate effectively improves the CPT through potentiostatic measurement [48]. In natural exposed conditions, corrosion is influenced by the atmosphere fluctuated with relative humidity [49]. In pitting corrosion, the effect of relative humidity on SS with $\mathrm{MgCl}_{2}$ has been investigated in situ microstructure studies. Many small pits are formed for nucleation between $33 \% \mathrm{RH}$ and $85 \% \mathrm{RH}$ or $33 \% \mathrm{RH}$ and $12 \% \mathrm{RH}$ at constant growth of single pit exposure.

\section{Stress Corrosion}

Stress corrosion is the growth of crack formation in a corrosive environment. It corrodes due to applied stress, which may be externally applied or residual, and it leads to sudden failure and normal ductility to tensile stress at high temperature. Table 9 portrays the experiments done on stress corrosion as a literature survey. The passivation film at the crack tip is broken due to plastic deformation. Metal (pure and normally) is 
exposed and attacked by corrosion. The growth rate is combined with corrosion and cracking. The crack begins to develop when stress concentration at the end of the crack exceeds the threshold stress intensity factor for stress corrosion cracking (KISCC).

Table 9. Benchmarking on experimental work in stress corrosion

\begin{tabular}{|c|c|c|c|c|}
\hline Authors & $\begin{array}{c}\text { Stress } \\
\text { corrosion } \\
\text { test }\end{array}$ & $\begin{array}{c}\text { Crack } \\
\text { measurement }\end{array}$ & $\begin{array}{c}\text { Surface } \\
\text { morphology }\end{array}$ & Fractography \\
\hline
\end{tabular}

Ulu Pauh \& Perlis [50]

Wenqian Zhang et al. [51]

Donghai Du et al. [52]

Xingfei Xie et al. [53]

Alyousif \& Nishimura [54]

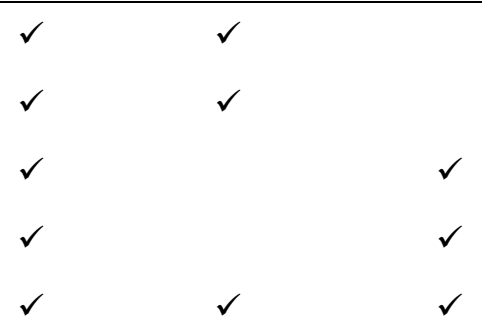

For stress corrosion cracking (SCC), initiated by stress concentration which defects the material surface and the load method is used on 304, 310, and 316 SS to examine along with the boiling saturated magnesium chloride solution [50]. The SCC occurs on stainless steel 316 with the boiling magnesium chloride solution [51]. From SCC initiation and propagation at different residual stresses, crack density is evaluated. From this experiment, the micro-crack was developed by cracking direction, micro-crack evolution process on the surface and the cracking types. The residual tensile stress in the machining affected layer has a great influence on stress corrosion cracking (SCC) microcracks (if critical stress is lesser than residual stress, micro-cracks will be initiated.) With the critical stress of $190 \mathrm{Mpa}$ on SS 316, the density has increased significantly to the early phase. Hence through the surface layer, the cracking is reduced.

The effects of SS 316 and 316L are studied to obtain SCC crack growth rates [52]. In hydrogenated water, the elevated crack growth rate up to $10^{-8}$ is generated in cold working. In 316 and 316L SS, the lowest crack growth is hydrogenated in pure water. For accelerating the crack growth rates, chloride has a small effect. The SCC investigation was carried out from the results. DO and chloride, which accelerate the SCC crack growth rate is the change in $\mathrm{pH}$ and destruction of the crack tip by chloride. Homogeneity and deformation level affect the morphology of the SCC fracture surface. At the higher-level cold work 316 stainless steel, transgranular cracking occurs. SCC behaviours of solutiontreated and cold-drawn 316 SS are investigated through a pressurized water reactor and the slow strain rate is observed on the tensile test [53]. During high $\mathrm{Cr}$ concentration containing oxides at transgranular stress corrosion cracking (TGSCC), crack initiation, oxygen dissolves and irregular water produce Fe-rich oxide which contains $\mathrm{Cl}$. For SCC, 
cold-drawn 316 stainless steel investigates in a simulated PWR environment and the micro-crack on 316 stainless steel in abnormal water $\mathrm{Cl}$ analysed by TEM. In stainless steels 304,310 and 316, the mechanism of stress corrosion cracking has been performed and it has been examined in a saturated magnesium chloride solution at boiling conditions using a constant load method [54]. In stainless steel, there is no inter-granular fracture, whereas only trans-granular fracture has been obtained. As same in SS 304 and 316, at high-temperatures of $416 \mathrm{~K}$ and $428 \mathrm{~K}$, the transgranular is obtained but intergranular has been obtained at a low temperature of $408 \mathrm{~K}$. The intergranular cracking is attributed to hydrogen embrittlement (HE) caused to the strain-induced formation of martensite with grain boundaries with hydrogen entry, And the transgranular cracking is active on corrosion nucleated at slip steps by dissolution.

\section{Surface modification in 316 stainless steel}

Corrosion based stainless steel 316 material is controlled by using protective coatings or surface modification/treatments. In stainless steel 316, several types of coating techniques are applied, such as magnetron sputtering, micro-arc oxidation, ion nitriding, sol-gel process, electrodeposition, shot peening, surface mechanical attrition treatment (SMAT), thermal spraying etc. From the laser surface melting, alloying and ion implantation can yield corrosion-resistant surfaces. From the following of surface modification, the various ways through which the corrosion behaviours of 316 Stainless Steel can be upgraded.

\section{Surface mechanical attrition treatment (SMAT)}

The corrosion behaviour of nanostructured 316 stainless steel has been experimented with through polarization test in $0.6 \mathrm{M} \mathrm{NaCl}$ aqueous solution at room temperature $[55,56]$. From the nanostructured layers, the surface mechanical attrition treatment (SMAT) and corrosion behaviour data of stainless steel 316 is obtained. From the potentiodynamic polarization test and electrochemical impedance spectroscopy (EIS) studies, low-temperature annealing and the combined SMAT effect are obtained. By the comparison of the 316 stainless steel corrosion resistance, the SMAT technique is suitable from other coating techniques in this study [57]. After this process, the treated surface is polished for reducing the oxidation effect and surface roughness.

\section{Magnetron Sputtering}

The electrochemical corrosion resistance of $\mathrm{MgZnCa}$ coating with stainless steel substrate is experimented with by magnetron sputtering deposition coating [58,59]. In this paper, $\mathrm{MgZnCa}$ alloy thin film coating on stainless steel and study on electrochemical was obtained. Using $\mathrm{MgZnCa}$ alloy, the surface of the materialhas been coated and subjected to magnetron sputtering treatments. From the present studies, the magnetron sputtering coating method achieves the thin film coating in which the uncoated materials are controlled. The coating thickness and corrosion resistance of the material are 
improved [60]. In polarization, the result shows that better corrosion resistance is obtained when the MgZnCa coating is applied to the material.

\section{Ion implantation}

Ion implantation is a technique used for surface modification of changing the surface chemistry of the material. From this technique, the adherent coating is experimented and observed that delay in crack initiation and enhanced fatigue life [61]. Low energy ion implementation is used to enhance the corrosion resistance, wearresistance and fatigue life of stainless steel 316. The Dual implantation on boron and nitrogen in stainless steel 316 is done and results shown that surface hardness and fatigue lifetime is enhanced up to $250 \%$.

\section{Surface coating on $316 S S$}

The surface modification techniques are results in thermochemical methods, ion implementation, laser modification and chemical or structural modification are done on base material only (stainless steel 316). These coating techniques are widely used to protect the surface damage on stainless steel 316 by wear, corrosion etc life $[61,62]$. Thermal spray coatings, sol-gel coating, physical vapour deposition are such surface coating for stainless steel 316 surface treatments.

\section{Conclusions}

A comprehensive work has been presented in this review paper to investigate several classifications of corrosion studies. The following are the collective observations that have been made:

- From cavitation corrosion, it is identified that the additives such as BMG and WC are added to show some enhancement on corrosion resistance through microstructural studies.

- From crevice corrosion, it is clear that some pre-treatment of bonded metal contact can be done to avoid corrosion. Some samples are done by $\mathrm{NaCl}$ in the effect of $\mathrm{HNO}_{3}$ and it enhances the result of crevice corrosion.

- From electrochemical corrosion, it is evident that the metal gets depolarization at atmospheric air, acids, and cation of less metal and in which, stainless steel 316 has been used in all solutions from high concentration to low concentration to obtain a better result in microstructure studies.

- From erosion-corrosion, it is found that the material has been investigated on the impingement angle with $\mathrm{NaCl}$ solution to obtain better erosion-corrosion resistance to prevent high damage to the material. 
- From fatigue corrosion, it is noted that in every join of the material, the sulphur or some additive material or solution is added with SS 316 to improve the corrosion resistance.

- From galvanic corrosion, it is understood that the polarization measurement has been taken by anode and cathode ratio tendencies. The material has been coupled with $10 \%$ wt of hydrochloric, phosphoric, and sulphuric solutions to avoid galvanic corrosion.

- From uniform corrosion, it is denoted that the stainless steel is prevented by using the coating method ( $\mathrm{TiN})$ and in other studies, the atomic layer deposition coating process has been done to prevent corrosion.

- From pitting and stress corrosion, it is evident that to avoid cracks, holes, and fractures, the biofilm has been added with some enhanced solution to improve the corrosion resistance.

\section{Acknowledgement}

The authors thank UGC-DAE CSR for their financial support to carry out this work (CSR-KN/CRS-115/2018-19/1053).

\section{References}

[1] H.S. Arora, A.V. Aditya, S. Mukherjee: In: The Minerals, Metals \& Materials Society Eds.: TMS, 144th Annual Meeting \& Exhibition, Springer, cham2015, p. 669-677.

[2] K.H. Lo, F.T. Cheng, C.T. Kwok, H.C. Man: Surf Coat Technol, 165 (2003) 258267.

[3] Y. Lei, H. Chang, X. Guo, T. Li, L. Xiao: Ultrason Sononchem, 39 (2017) 77-86.

[4] G. Salvago, G. Fumagalli, A. Mollica, G. Ventura: Corros Sci, 27 (1987) 927-936.

[5] J. Buhagiar, A. Spiteri, M. Sacco, E. Sinagra, H. Dong: Corros Sci, 59 (2012) 169178.

[6] J.L. Dawson, M.G. Ferreira: Corros Sci, 26 (1986) 1027-1040.

[7] D. Chen, Han EH, Wu X: Corros Sci, 111 (2016) 518-530.

[8] T. Aoyama, Y. Sugawara, I. Muto, N. Hara: Corros Sci: 127 (2017) 131-140.

[9] G. Bäck, P.M. Singh: Corros Sci, 46 (2004) 2159-2182.

[10] P.T. Jakobsen, E. Maahn: Corros Sci, 43 (2001) 1693-1709.

[11] E. Shojaei, M. Mirjalili, M.H. Moayed: Corros Sci, 156 (2019) 96-105. 
[12] Anwar, Ul-Hamid, Huseyin Saricimen, Abdul Quddus, Abdulrashid I Mohammed, M. Luai, Al-Hems: Corros Eng Sci Techn: 52 (2017) 134-140.

[13] C.A. Loto, O.S. Fayomi, R.T. Loto: Int J Electrochem, 7 (2012) 3787-3797.

[14] A. Galal, N.F. Atta, M.H. Al-Hassan: Mater Chem Phys, 89 (2005) 38-48.

[15] M.C. Li, C.L. Zeng, H.C. Lin, C.N. Cao: Br Corrosion J, 36 (2001) 179-183.

[16] M.C. Li, C.L. Zeng, S.Z. Luo, J.N. Shen, H.C. Lin, C.N. Cao: Electrochim Acta, 48 (2003) 1735-1741

[17] C.A. Loto: J Chem Inf Model, 53 (2013) 1689-1699.

[18] La Barbera, A. Mignone, S. Tosto, C. Vignaud: Surf Coat Technol, 46 (1991) $317-$ 329.

[19] M.G. Pujar, R.K. Dayal, S.N. Malhotra, T.P.S Gill: J Mater Eng Perform, 14 (2005) 327-342.

[20] Y. Yi, P. Cho, A. Al Zaabi, Y. Addad, C. Jang: Corros Sci, 74 (2013) 92-97.

[21] J.K. Wendt, D.T. Chin: Corros Sci, 25 (1985) 901-915.

[22] T.O. Olugbade, J. Lu: Journal of Bio-and Tribo-Corrosion, 5 (2019) 38.

[23] Ajay K Singh, Vipin Chaudhary, A. Sharma: Electrochimica Acta, 30 (2012) 99 109.

[24] N. Andrews, L. Giourntas, A.M. Galloway, A. Pearson: Wear, 320 (2014) 143 151.

[25] D.G. Li, D.R. Chen, P. Liang: Ultrason Sononchem, 35 (2017) 375-381.

[26] Y. Zhao, F. Zhou, J. Yao, S. Dong, N. Li: Wear, 328 (2015) 464-474.

[27] S.Y. Lee, C.J. Coronella, J.D. Seader, C.H. Pitt: Chem Eng Sci, 48 (1993) $1437-$ 1445 .

[28] X. Zhang, J. Wang, H. Fan, D. Pan: Appl Surf Sci, 440 (2018) 755-762.

[29] H. Dong, Q.I. PY, X.Y. Li, R.J. Llewellyn: Mater Sci Eng, 431 (2016) 137-145.

[30] R.J. Wood, J.C. Walker, T.J. Harvey, S. Wang, S.S. Rajahram: Wear, 306 (2013) 254-262.

[31] K. Mukahiwa, F. Scenini, M.G. Burke, N. Platts, D.R. Tice, J.W. Stairmand: Corros Sci, 131 (2018) 57-70.

[32] A. Poonguzhali, S. Ningshen, G. Amarendra: Procedia Structural Integrity, 14 (2019) 705-711.

[33] J. Gao, J. Tan, X. Wu, S. Xia: Corros Sci, 152 (2019) 190-201. 
[34] Y. Peng, Z. Liu, C. Chen, J. Gong, M.A. Somers: Mater Sci Eng. A, 769 (2020) 1385-1424.

[35] H.S. Kim, H.B. Lee, J. Chen, C. Jang, T.S. Kim, G.L. Stevens, K. Ahluwalia: Corros Sci, 151 (2019) 97-107.

[36] Z. Zhang, J. Tan, X. Wu, E.H. Han, W. Ke, J. Rao: Corros Sci, 146 (2019) 80-89.

[37] B. Fereidooni, M.R. Morovvati, S.A Sadough-Vanini: Ultrasonics, 88 (2018) 137147.

[38] R. Moshrefi, M.G. Mahjani, A. Ehsani, M. Jafarian: Anti-Corros Method M, 58 (2011) 250-257.

[39] M.E. El-Dahshan, A.S. El Din, H.H. Haggag: Desalination, 142 (2002) 161-169.

[40] M. Finsgar: Corros Sci, 68 (2013) 51-56.

[41] M. Li, S. Luo, C. Zeng, J. Shen, H. Lin: Corros Sci, 46 (2004) 1369-1380.

[42] E. Marin, A. Lanzutti, L. Guzman, L. Fedrizzi: J Coat Technol Res, 8 (2011) 655659.

[43] Y.W. Hao, B. Deng, C. Zhong, Y.M Jiang, J. Li: J Iron Steel Res Int, 16 (2009) $68-72$.

[44] X. Sheng, Y.P. Ting, S.O.Pehkonen: Corros Sci, 49 (2007) 2159-2176.

[45] M. Talebian, K. Raeissi, M. Atapour, B.M. Fernández-Pérez, A. Betancor-Abreu, I. Llorente, S. Fajardo, Z.Salarvand, S. Meghdadi, M. Amirnasr, R.M. Souto: Corros Sci, 160 (2019) 108-130.

[46] C. Prieto, D. Young, M. Singer, M. Clum, T.J. Cyders: In Proceedings Nace Corrosion, (2018) 1-17.

[47] M.A. Naghizadeh, D. Nakhaie, M. Zakeri, M.H. Moayed: Corros Sci, 94 (2015) 420-427.

[48] M. Zakeri, D. Nakhaie, M.A. Naghizadeh, M.H. Moayed: Corros Sci, 93 (2015) 234-241.

[49] L. Guo, S.R Street, H.B Mohammed-Ali, M. Ghahari, N. Mi, S. Glanvill, A. Du Plessis, C. Reinhard, T. Rayment, A.J. Davenport: Corros Sci, 150 (2019) 110120.

[50] Ulu Pauh: Procedia Eng, 53 (2013) 650-654.

[51] W. Zhang, K. Fang, Y. Hu, S. Wang, X. Wang: Corros Sci, 108 (2016) 173-184.

[52] D. Donghai, C. Kai, L. Hui, Z. Lefu, S. Xiuqiang, X. Xuelian, L. Andresen Peter: Corros Sci, 110 (2016) 134-142.

[53] X. Xie, D. Ning, B. Chen, S. Lu, J. Sun: Corros Sci, 112 (2016) 576-584. 
[54] O.M. Alyousif, R. Nishimura: Corros Sci, 49 (2007) 3040-3051.

[55] T.O. Olugbade, C. Liu, J. Lu: Advanced Engineering Materials, 8 (2019) 1900125.

[56] T.O. Olugbade, J. Lu: Analytical Letters, 52 (2019) 2454-71.

[57] T.O. Olugbade: Data in brief, 25 (2019) 104033.

[58] T.O. Olugbade, T.E. Abioye, P.K. Farayibi, N.G. Olaiya, B.O. Omiyale, T.I. Ogedengbe: Analytical Letters, (2020) 1-5.

[59] T.O. Olugbade: Analytical Letters, (2020) 1-3.

[60] T.O. Olugbade: Corrosion Reviews, 38 (2020) 1.

[61] P. Shankar, U.K. Mudali: Mechanism, Mitigation and Monitoring, (2002) 340.

[62] M. Uthayakumar, M. Adam Khan, S. Thirumalai Kumaran, Adam Slota, Jerzy Zajac: Materials and Manufacturing Processes, 31 (2016) 1733-1739.

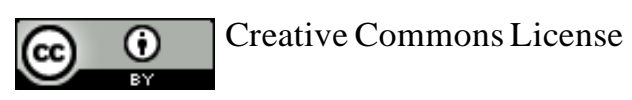

This work is licensed under a Creative Commons Attribution 4.0 International License. 